\title{
Effects on auditory function of chronic exposure to electromagnetic fields from mobile phones
}

\author{
Maha Ahmed AhmedEbrahim lecture in audiology Unit S
}

\begin{abstract}
The widespread use of mobile phones has given rise to apprehension regarding the possible hazardous health effects of high-frequency electromagnetic fields (EMFs) on auditory function. We conducted a study to investigate the effects of long-term ( $>4$ yr) exposure to EMFs emitted by mobile phones on auditory function. My study population was made up of 40 healthy medical students - 31 men and 9 women, aged 20 to 30 years (mean 22.7). Of this group, 31 subjects typically held their phone to the right ear and 9 to the left ear; the non-phone-using ear served as each subject's control ear. The phone-using subjects were also split into two groups of 20 based on the duration of their daily phone use ( $\leq 60 \mathrm{~min}$ vs. $>60 \mathrm{~min})$. All subjects underwent pure-tone audiometry, speech audiometry, impedance audiometry, and brainstem evoked response audiometry (BERA), and comparisons were made between the phone-using ear and the control ear and between the shorter and longer duration of daily use. We found no statistically significant differences in high-frequency puretone average between the phoneusing ears and the control ears $(p=0.69)$ or between the shorter- and longer-duration phone-using ears $(\mathrm{p}=0.85)$. Moreover, statistical analysis of BERA findings revealed no significant differences between the phoneusing ears and the control ears in terms of wave I-III, III-V, and I-V interpeak latencies ( $\mathrm{p}=0.59,0.74$ and 0.44 , respectively). None of the subjects reported any subjective symptoms, such as headache, tinnitus, or sensations of burning or warmth behind, around, or on the phone-using ear. I conclude that the long-term exposure to EMFs from mobile phones does not affect auditory function.
\end{abstract}

\section{Introduction}

In recent years, the use of mobile phones has increased tremendously, and there are more than 1.6 billion users worldwide.(Kayabasoglu et al.,2011) The widespread use of mobile phones has given rise to speculation regarding the possible hazardous health effects of high-frequency electromagnetic fields (EMFs). Mobile phones transmit and receive microwave radiation at frequencies mainly between 800 and 2,000 MHz(Dimbylow et la.,1994). These frequencies excite the rotation of water and some organic molecules, but they are not ionizing, and they are not believed to cause damage to DNA. However, EMF radiation has been attributed to thermal and nonthermal effects on humans(Heynicket al.,2003). The reported thermal effects of mobile phones include headache, a sensation of burning and warmth in the ear area, a burning sensation on the facial skin, and alterations in the blood-brain barrier.4-6 Nonthermal effects include modification of sleep patterns, an increase in blood pressure, and alterations in cognitive functions.( Braune et al.,1998\&Borbély et al.,1999)The idea that EMFs have a carcinogenic effect is controversial. Only a few studies have been undertaken to assess the effects of long-term exposure to electromagnetic waves from mobile phones on hearing in human beings. In this article, we describe our investigation of auditory function and long-term exposure to EMFs from mobile 
phones(Kerekhanjanarong et al .2005\&.Oktay et al.,2004)

\section{Patients and methods}

My study population was drawn from a group of medical students who had been regular mobile phone users for at least 4 years. All prospective participants provided a detailed history, with particular emphasis on the duration of mobile phone use, the preferred side of use (phone-using ear), the presence or absence of a warm sensation in the area of the phoneusing ear, and a history of headache, hearing loss, tinnitus, vertigo, and aural fullness. We did not include any students with a history of ear discharge, hearing loss, ear surgery, ototoxic medication use, prolonged noise exposure, or any systemic disease that would affect hearing. We also excluded subjects who used their mobile phone with both ears. Otoscopic examinations had been performed by an otolaryngologist (S.B.) to rule out any external and middle ear pathology. A total of 40 subjects - 31 men and 9 women, aged 20 to 30 years (mean 22.7) - who met our eligibility criteria were selected for inclusion in the study. Of this group,
31 subjects typically held their phone to the right ear and 9 to the left ear; the non-phone-using ear served as each subject's control ear. The subjects were also split into two groups of 20 based on the duration of their daily phone use ( $\leq 60 \mathrm{~min}$ vs. $>60 \mathrm{~min}$ ). Pure-tone audiometry, speech audiometry, impedance audiometry, and brainstem evoked response audiometry (BERA) were performed on all subjects. The audiometric measurements included frequencies from 0.25 to $16 \mathrm{kHz}$, and findings in the phone-using ear were compared with those in the control ear; comparisons were also made in the phone-using ears of the shorterduration ( $\leq 60 \mathrm{~min})$ and longer-duration (>60 min) groups. For the BERA measurements, the same comparisons were made in the wave I-III, III-V, and $\mathrm{I}-\mathrm{V}$ interpeak latencies.

Statistical analysis. The chi-square test was applied for comparisons of observation between the two groups and the Student $t$ test was applied for comparisons of variable data.

Ethical considerations. Approval for the study protocol was granted by our institution's Ethics Committee.

\section{Results}

Pure-tone audiometry revealed that no patient experienced a hearing loss - defined as a pure-tone average (PTA) of $>25 \mathrm{~dB}$ at $0.5,1,2$, and $3 \mathrm{kHz}$ - in either ear. When the high-frequency PTA-defined as the average over $4,8,12$, and $16 \mathrm{kHz}$-was compared, abnormal hearing was found in 5 of the 40 phone-using ears $(12.5 \%)$ and in 3 of the 40 control ears (7.5\%), which was not a statistically significant difference (table 1).

\begin{tabular}{|l|l|l|l|l|}
\hline HFPTA & Phone using ear & Control ear & total & P value \\
\hline $\begin{array}{l}<=25 \mathrm{~dB} \text { (Normal } \\
\text { hearing) }\end{array}$ & $35(87.5)$ & $37(92.5)$ & $72(90.0)$ & 0.69 \\
\hline $\begin{array}{l}>25 \mathrm{~dB} \text { (hearing } \\
\text { loss) }\end{array}$ & $5(12.5)$ & $3(7.5)$ & $8(10.0)$ & \\
\hline
\end{tabular}

Table 1. Comparison of pure-tone average findings in the mobile-phone-using ears $(n=$ 40) and the control ears $(n=40)$

Similarly, no statistically significant difference in highfrequency PTAs was seen according to the duration of phone use (table 2). Statistical analysis of the BERA data found no statistically significant differences in the wave I-III, wave III-V, and wave I- 
$\mathrm{V}$ interpeak latencies between the phoneusing ears and the control ears (table 3). Moreover, there were no differences in these latencies according to the duration of use (table 2). Finally, no patient reported any sensations of burning or warmth behind, around, or on the ear, and none complained of headache, fullness, or tinnitus.

\begin{tabular}{|l|l|l|l|}
\hline & Phone using ear & Control ear & P-value \\
\hline HFPTA & $14.83 \pm 7.28$ & $14.93 \pm 7.48$ & 0.69 \\
\hline I-III latency & $2.09 \pm 0.19$ & $2.07 \pm 0.18$ & 0.59 \\
\hline III-V latency & $1.99 \pm 0.34$ & $1.97 \pm 0.19$ & 0.74 \\
\hline I-V latency & $4.03 \pm 0.29$ & $3.98 \pm 0.27$ & 0.44 \\
\hline
\end{tabular}

Table 3. Comparison of audiometric parameters in the mobile-phone-using ears $(n=40)$ and the control ears $(n=40)$

\section{Discussion}

There has been considerable interest recently in the possible biologic effects of human exposure to EMFs emitted from mobile phones. Although EMFs can exert thermal effects by heating, mobile phones operate at a power level at which overt heating does not occur. Most studies have now focused on whether there are any adverse biologic nonthermal effects of frequent and long-term exposure to EMFs. Lowenergy EMFs $(\leq 450 \mathrm{MHz})$ appear to cause structural and functional changes in cell membranes, leading to an abnormal cell response. Frequencies between 800 and $1,800 \mathrm{MHz}$ can cause nonthermal effects on the structure and function of cytoplasm, inducing changes in the electrophysiology of living cells(Panda et al.,2010). The degree of internal exposure to EMFs from mobile phones can be quantified by the amount of energy absorbed by a unit mass of the object, which is expressed as the specific absorption rate (SAR) in units of $\mathrm{W} / \mathrm{kg}$ (Szentpá.,1999). The standards set by national and international institutions limit the SAR to a range of 1.6 to $2 \mathrm{~W} / \mathrm{kg}$ for local exposure in the general public. Because of the proximity of mobile phones to the head during use, the brain and auditory system are exposed to a higher SAR than is the rest of the body. The biologic effects of EMFs depend on both the frequency and intensity of radiation, the duration

of exposure, and the individual characteristics of a given person's nervous system and immune status(Hermann et al.,1997\&Panda2010). Various studies have addressed the short-term effects of acute exposure to mobile phones on hearing(Arai et al2003 \&.Mora et al.,2006). However, data are still lacking in terms of frequent and long-term exposure to low-level EMFs on the human auditory system(Kerekhanjanarong et al.,2005). Davidson and Lutman reported no chronic effects of cell phone use in terms of hearing, tinnitus, and balance in a student population with the help of questionnaires(Davidson and Lutman .2007). In this study, none of the subjects reported any subjective symptoms related to mobile phone use, such as a heat sensation around the ear, headache, fullness, or tinnitus. Our findings are in agreement with those of (Hietanen et al.2002) However, other authors have reported various subjective symptoms, especially a thermal sensation around the ear, among extensive mobile phone users(Oktay MF, Dasdag.,2006)..In this study comparison of high-frequency PTAs found no statistically significant difference in hearing thresholds between the phone-using ears and the control ears. This finding supports 
observations made by others. For example, Kerekhanjanarong et al found no significant difference in hearing thresholds between dominant and nondominant ears.(Kerekhanjanarong et al.,2005) Likewise, Panda et al found no significant difference in hearing loss at the speech frequencies and at the high frequencies between phone users and controls in either ear(Panda et al., 2010). However, contrary findings were reported by GarcíaCallejo et al, who concluded that frequent mobile phone use over 3 years was correlated with a mild hearing loss of 1 and $5 \mathrm{dBHL}$ that was not observed in non-mobile-phone users(GarcíaCallejo et al.,2005). Panda et al compared high-frequency audiometric results and found that those who used their phones for more than 60 minutes per day had significantly greater high-frequency PTA than those who used them less(Panda et al.,2010). In contrast, I found no significant differences in high-frequency PTAs between those who used their phone less than 60 minutes per day and more frequent users. A possible explanation for this is the small size of our study sample; other factors might be age, signal strength, the proximity of a user's residence or workplace to a base station or television tower, and other environmental influences. Oysu et al studied the short-term effects of exposure to mobile phone EMFs on auditory brainstem responses (ABRs) in healthy human volunteers and found no changes in the absolute latencies and interpeak latencies.(Oysu et al.,2005) Arai et al exposed 15 healthy volunteers with normal hearing to mobile phone radiation for 30 minutes; no changes were noted in waves I, III, and V, in ABR, and in midlatency response after 30 minutes of exposure(Arai et al.,2003). Similarly, Bak et al evaluated the effects that electromagnetic radiation has on ABRs during and after the use of a mobile phone, and they observed no differences in wave I, III, and V latencies or in interpeaklatencies(Bak ET AL.,2003).Oktay and Dasdag found no differences in wave I, III, and $\mathrm{V}$ latencies or in interpeak latencies among nonusers, moderate users, and intensive users(Oktay and Dasdag., 2006) .I also found no statistically significant difference in wave I-III, III$\mathrm{V}$, and $\mathrm{I}-\mathrm{V}$ interpeak latencies between the phone-using ears and the controls, and no differences in terms of the duration of use. The only study we know of that contradicts the findings of the other BERA studies was published Kellényi et al, who reported a $0.2-\mathrm{ms}$ delay in wave $\mathrm{V}$ after 15 minutes of EMF cellular phone exposure in 10 normal-hearing subjects (mean age: $29.3 \mathrm{yr}) .30 \mathrm{In}$

\section{Conclusion}

There was no adverse effect on the auditory system from chronic exposure to EMFs by mobile phones, as measured by changes in pure-tone audiometry and BERA. More followup studies are needed to evaluate the effects of frequent and long-term mobile phone use on hearing on a large sample size before we can reach any definitive conclusions.

\section{References}

1. Kayabasoglu G, Sezen OS, Eraslan G, et al. Effect of chronic exposure to cellular telephone electromagnetic fields on hearing in rats. J LaryngolOtol 2011;125(4):348-53.

2. Dimbylow PJ, Mann SM. SAR calculations in an anatomically realistic model of the head for mobile communication transceivers at 900 $\mathrm{MHz}$ and $1.8 \mathrm{GHz}$. Phys Med Biol 1994;39(10):1537-53.

3. Heynick LN, Johnston SA, Mason PA. Radio frequency electromagnetic fields: Cancer, mutagenesis, and 
genotoxcity. Bioelectromagnetics 2003;Suppl 6:S74-100.

4. Frey AH. Headaches from cellular telephones: Are they real and what are the implications? Environ Health Perspect 1998;106(3):101-3.

5. Oftedal G, Wilén J, Sandström M, Mild KH. Symptoms experienced in connection with mobile phone use. Occup Med (Lond) 2000;50(4):237-45.

6. Fritze K, Sommer C, Schmitz B, et al. Effect of global system for mobile communication (GSM) microwave exposure on blood-brain barrier permeability in rat. ActaNeuropathol 1997;94(5):465-70.

7. Braune S, Wrocklage C, Raczek J, et al. Resting blood pressure increase during exposure to a radio-frequency electromagnetic field. Lancet 1998;351(9119):1857-8. 8. Borbély AA, Huber R, Graf T, et al. Pulsed high-frequency electromagnetic field affects human sleep and sleep electroencephalogram. NeurosciLett 1999;275(3):207-10.

9. Preece AW, Iwi G, Davies-Smith A, et al. Effect of a $915-\mathrm{MHz}$ simulated mobile phone signal on cognitive function in man. Int $\mathbf{J}$ RadiatBiol 1999;75(4):447-56.

10. Repacholi MH, Basten A, Gebski V, et al. Lymphomas in $\mathrm{E}$ mu-Pim1 transgenic mice exposed to pulsed 900 MHZ electromagnetic fields. Radiat Res 1997;147(5):631-40.

11. Burkhardt M, Spinelli Y, Kuster N. Exposure setup to test effects of wireless communications system on the CNS. Health Phys 1997;73(5):770-8.

12. Kerekhanjanarong V, Supiyaphun P, Naratricoon J, Laungpitackchumpon P. The effect of mobile phone to audiologic system. J Med Assoc Thai 2005;88(Suppl 4):S231-4.

13. Oktay MF, Dasdag S. Effects of intensive and moderate cellular phone use on hearing function. ElectromagnBiol Med 2006;25(1):1321.

14. Oktay MF, Dasdag S, Akdere M, et al. Occupational safety: Effects of workplace radiofrequencies on hearing function. Arch Med Res 2004;35(6):517-21.
15. Panda NK, Jain R, Bakshi J, Munjal $\mathrm{S}$. Audiologic disturbances in longterm mobile phone users. J Otolaryngol Head Neck Surg 2010;39(1):5-11.

16. Independent Expert Group on Mobile Phones. Mobile phones and health. Chilton, Oxfordshire, U.K.: National Radiological protection Board; 2000. Availablehttp://www.femp.es/files/358 $\underline{0-254-}$ fichero/06\%20\%20Informe $\% 20$ Stewart \%202000.pdf.Accessed June 9, 2016.

17. Szentpáli B. Human exposure to electromagnetic fields from mobile telephones. Presented at: 4th International Conference on Communications in Modern Satellite, Cable, and Broadcasting Services. Nis, Yugoslavia: Institute of Electrical and Electronics Engineers; Oct. 13-15, 1999; Nis, Yugoslavia.

18. IEEE standard for safety levels with respect to human exposure to radio frequency electromagnetic fields, $3 \mathrm{kHz}$ to $300 \mathrm{GHz}$. New York: Institute of Electrical and Electronics Engineers; 1992.

Hermann DM, Hossmann KA. Neurological effects of microwave exposure related to mobile communication. J NeurolSci 1997;152(1):1-14.

20. Galeev AL. Effects of the microwave radiation from the cellular phones on humans and animals [in Russian]. Ross FiziolZhIm I M Sechenova 1998;84(11):1293-1302.

21. Galeev AL. The effects of microwave radiation from mobile telephones on humans and animals.NeurosciBehavPhysiol 2000;30(2):187-94.

22. Arai N, Enomoto H, Okabe S, et al. Thirty minutes mobile phone use has no short-term adverse effects on central auditory pathways. ClinNeurophysiol 2003;114(8):1390-4.

23. Uloziene I, Uloza V, Gradauskiene E, Saferis V. Assessment of potential effects of the electromagnetic fields of mobile phones on hearing. BMC Public Health 2005;5:39.

24. Mora R, Crippa B, Mora F, Dellepiane M. A study of the effects of cellular telephone microwave radiation on the 
auditory system in healthy men. Ear Nose Throat J 2006;85(3):160, 162-3.

25. Davidson HC, Lutman ME. Survey of mobile phone use and their chronic effects on the hearing of a student population.Int J Audiol 2007;46(3):113-18.

26. Hietanen $\mathrm{M}$, Hämäläinen $\mathrm{AM}$, Husman T. Hypersensitivity symptoms associated with exposure to cellular telephones: No causal link. Bioelectromagnetics 2002;23(4):26470.

27. GarcíaCallejo FJ, GarcíaCallejo F, Peña Santamaria J, et al. Hearing level and intensive use of mobile phones [in Spanish]. ActaOtorrinolaringolEsp 2005;56(5):187-91.
28. Oysu C, Topak M, Celik O, et al. Effects of the acute exposure to the electromagnetic field of mobile phones on human auditory brainstem responses. Eur Arch Otorhinolaryngol 2005;262(10):839-43.

29. Bak M, Sliwinska-Kowalska M, Zmyslony M, Dudarewicz A. No effects of acute exposure to the electromagnetic field emitted by mobile phones on brainstem auditory potentials in young volunteers. Int $\mathbf{J}$ Occup Med Environ Health 2003;16(3):201-8. 30. Kellényi L, Thuróczy G, Faludy B, Lénárd L. Effects of mobile GSM radiotelephone exposure on the auditory brainstem response (ABR). Neurobiology (Bp) 1999;7(1):79-81. 